GUILLERMO ARRIAGA, EL CAZADOR DE HISTORIAS

Luis José Galvis Díaz 


\section{GUILLERMO ARRIAGA, EL CAZADOR DE HISTORIAS}

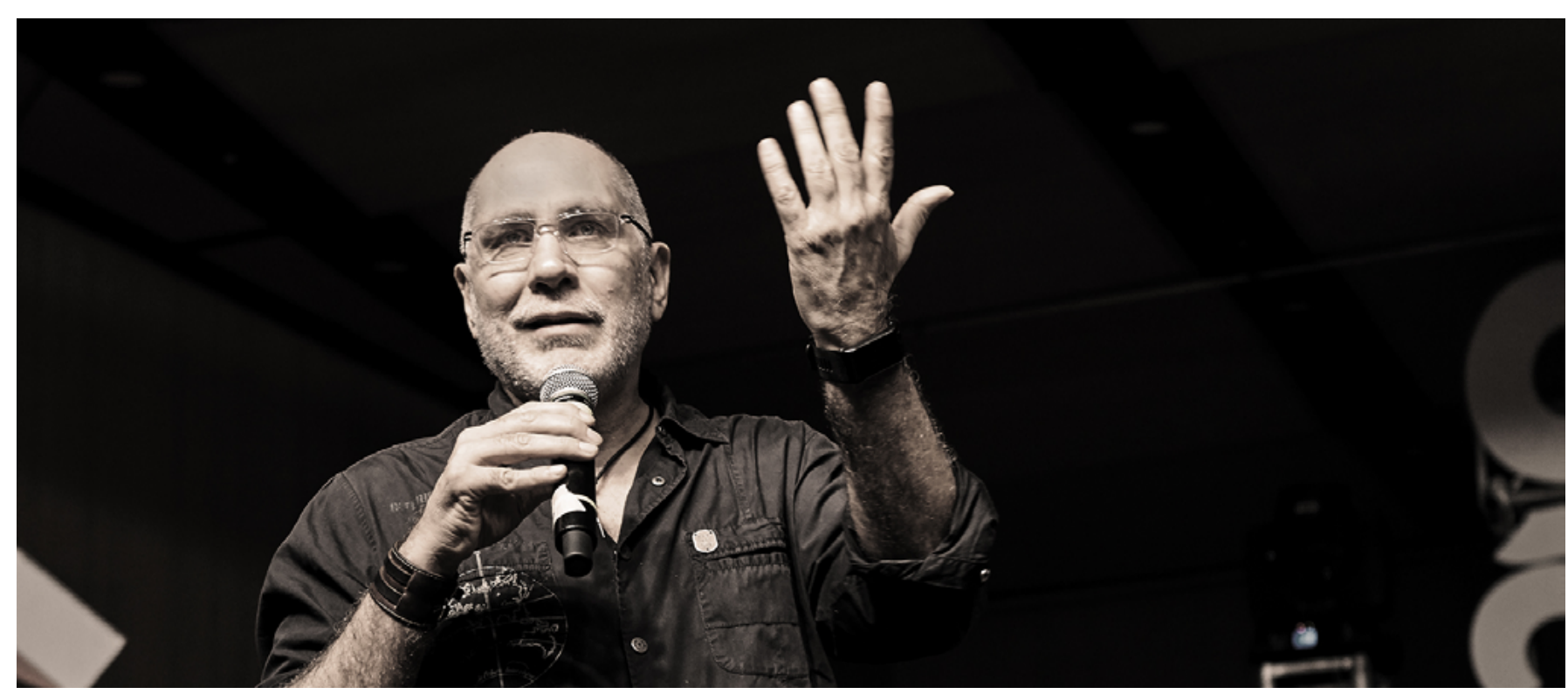

Guillermo Arriaga, Entrevista ULIBRO 2017. Foto: Andrés Serrano

Aunque quisiera pasar inadvertido, esconder los 1.88 metros de su estatura es una tarea difícil para el escritor mexicano Guillermo Arriaga. Aunque por su apariencia puede lucir más como boxeador que como escritor, él no pudo pasar inadvertido en su visita a la Feria del Libro, Ulibro 2017, de la Universidad Autónoma de Bucaramanga, donde presentó su más reciente novela, "El Salvaje". Esa misma estatura fue la causante de tantas peleas en su adolescencia, porque los jóvenes más grandes de su barrio lo buscaban para pelear, aunque él fuera mucho menor que ellos. $Y$ aunque lo rompieron a puñetazos con tal dureza que quedó con la pérdida del sentido del olfato, Guillermo aprendió a defenderse para sobrevivir y estas experiencias de su barrio, en Ciudad de México, las contó tanto a la literatura como al cine. Con la mirada y la paciencia del cazador que es, él estuvo relatando historias de su vida que se han entrelazado con sus ficciones.
La T3RA: En tu más reciente novela, "El salvaje", hay un componente narrativo que es la cacería. Uno de los personajes es Amaruq, un nativo en el río Yukón que persigue a un lobo y, asimismo, en Ciudad de México hay una cacería humana al personaje de Carlos, el hermano de Juan Guillermo el protagonista de la novela. ¿Por qué la pasión por la cacería en tu vida y en tus obras?

GA: Cuando digo que soy cazador, las opiniones son muy divididas. Hay quien me mienta la madre, quien me insulta, quien no entiende, pero no es una afición la cacería. La cacería es un rito y una forma que permite romper en contra de la alienación. Nosotros no sabemos de dónde vienen las cosas, no sabemos de dónde viene la carne que nos comemos, nunca vemos 
cómo matan las vacas, nunca vemos cómo se matan las gallinas, simplemente, nos las comemos. A menos que vengamos del campo, no sabemos de dónde viene la tela de nuestros pantalones, no sabemos de dónde vienen nuestras zanahorias. No sabemos cómo funciona un celular o cómo funciona un avión. El cazador sí y, por eso, él puede cerrar un círculo. El cazador entiende cuál es la presa, dónde duerme, cómo son sus huellas, cuando se reproduce, cuando la puede cazar y cuando no. Poco a poco, empieza a sentir que pertenece a la presa, esa es la importancia de la cacería que hace que pertenezcas a este mundo.

Vivimos en un trono de sangre y estamos sentado sobre él. Los vegetarianos dicen que no matan nada y es porque no quieren ver la realidad. Para poder sembrar zanahorias deben arrasar bosques, y así, hay muerte. El algodón que traemos, el petróleo que usamos destruye. Lo único que hace un cazador, en vez de estar pagándoles a otros porque maten, es que él caza su comida. Yo quiero aclarar que yo solo cazo con arco, flecha o cuchillo, no utilizo armas de fuego. Entonces, la dificultad de poder cazar un animal es muy alta. Primero porque debes estar muy cerca y una vez que estás cerca, el movimiento de abrir un arco, es muy aparatoso y hace que el animal se vaya.

Si tú me preguntas qué es una pasión, la palabra pasión significa padecimiento, es algo que se padece y yo desde los tres años quería ser cazador. Cuando era chiquito, me obsesionaron tres cosas: las mujeres me parecían el invento más maravilloso hecho sobre la tierra; cazar, lo que ha ido matizando mi vida; y escribir. Yo pienso como cazador, escribo como cazador, dirijo como cazador y pues no podía dejar de hacerlo en mi nueva novela.

En "El Salvaje", un muchacho de 14 años que se llama
Juan Guillermo vive en el barrio Unidad Modelo, un barrio de clase media baja y bravo, que es el barrio en el que yo crecí. Le asesinan a su hermano y su familia queda muy triste. Su abuela muere de tristeza, se siente culpable de lo que le pasó, de no haber cuidado a su nieto de 21 años. Ella muere viendo la televisión y los padres mueren en un accidente de carretera. Este muchacho queda completamente solo y debe tomar dos decisiones importantes: cómo sobrevivir y si debe vengarse de los asesinos de su hermano, quienes lo cazaron. Por otra parte, está la historia de un hombre que se llama Amaruq, un indígena inuit que en Canadá se dedica a vender pieles de lobos y va a buscar un lobo en especial. Amaruq significa lobo y su abuelo, quien lo entrenó, le dice que de todos los lobos que va a cazar uno de ellos es su dueño, si no lo caza en esta vida está condenado a cazarlo en sucesivas vidas. Amaruq se lanza a cazar este enorme lobo quien en vez de ir al sur en invierno, se va hacia el norte, en donde el clima es más inclemente. Es un invierno muy crudo y ahí va persiguiendo esa jauría de lobos buscando a este lobo en particular y se mete cada vez más a territorio desconocido. Él no sabe si ya se murió o esta alucinando. Poco a poco, esta historia que parece que no tiene nada que ver con la historia de Juan Guillermo, se va juntando poco a poco, entre los $8000 \mathrm{~km}$ que hay entre Yukón y Ciudad de México

La T3RA: Una presencia que hay en esta novela y en otras de tus obras, es la de los caninos. En el caso del lobo en la vida salvaje y en el caso de los perros en la vida doméstica. ¿En qué momento decides que ellos son domésticos y en qué momento decides que ellos atacan?

GA: En "El salvaje", los animales son muy importantes $y$, también, el amor que hay hacia ellos. Estamos acostumbrados a que las mascotas sean animales 
domesticados, les arrebatamos su "perredad". A los perros los ponemos suavecitos, les ponemos chalequitos, les ponemos campanitas, no los dejamos ser perros, que me parece una crueldad animal. La otra vez había una señora que le da reiki a sus gatos, pobres gatos. Creemos que queremos mucho a nuestras mascotas, pero, realmente le estamos quitando su ser, queremos que se comporten como niños, como Barbies y Kents. Son juguetes: los vestimos, los disfrazamos, siéntate, párate, ve, trae.

Hay una mascota en esta novela que se llama Colmillo, un perro lobo que al dueño le da miedo porque es un perro que te puede matar. Yo tuve un perro callejero, corriente, feísimo que se llamaba "Coffee" y que tenía ocho años. Donde yo crecí había peleas de perros y una vez aventaron a mi perro con el campeón de peleas para que lo matara. Mi perro no era tan grande y el otro era un pastor alemán que acababa de ganar una pelea. Cuando llegó el pastor alemán a matar a mi perro, mi perro se echó hacia atrás, lo agarró de la garganta y lo mató. Y esto, me sirvió para escribir una película llamada "Amores perros". A "Coffee" lo empezaron a llevar mis vecinos a pelear y mató una gran cantidad de perros. Era muy salvaje y a veces lo veía y me daba miedo mi propio perro, el que yo amaba con toda mi alma.

Una vez este perro -y esto viene en la novela-, vio a un mecánico que estaba arreglando el coche del vecino, salió corriendo, le brincó, le mordió en el bíceps se dejó caer y se lo arrancó. ¿Sabes lo que es un perro le arranque el bíceps a una persona? Luego, a una señora la arrancó la nalga, literal, la desnalgó. Entonces, así con las mascotas tenemos una relación. Yo adoraba a mi perro y el que tengo ahora también. Es un Cocker y no es el más fiero. Pero sí, a veces las mascotas tienen que confrontarte $y$, entre ellas, mi animal favorito es el perro. Tanto es mi animal favorito, que nuestro equipo de futbol de la calle donde vivíamos se llamaba "Canes" y éramos los canes del barrio Unidad Modelo. $Y$ ese amor por los perros se tiene que traducir, y el del lobo, del que se supone es el animal de donde vienen todos los perros. Aunque uno no se explica cómo un chihuahua o un caniche pueden venir del lobo.

La T3RA: ¿Cómo nace esta novela y la obsesión por escribir esta historia?

GA: Escribir "El Salvaje" me llevó cinco años y medio y 14 kilos, porque subí 14 kilos, ya que me dediqué a ella de 14 o 16 horas diarias. Dejé de ir al gimnasio y hacer ejercicio. Parecía como si acabara de parir, y al contrario de las mujeres que tienen un hijo, yo no recuperé la forma.

Yo no tengo mucha idea de lo que voy a escribir. Lo que quiero es poner cosas que me pasaron a mí. Por ejemplo, te voy a decir cosas que pasaron durante mi generación, porque esta novela se lleva a cabo en los años 60, y en México hubo una matazón de estudiantes y el gobierno venía con lo de las Olimpiadas del 68. Empezaron a hacer una cosa que se llama micro represión, eso significa intimidar a cualquier niño o joven que estuviera en la calle. Si yo estaba jugando en la calle y llegaban unas camionetas cerradas, que se llamaban "julias", con dos policías, nos correteaban con macanas. Yo con apenas 10 años de edad, no me salvaba de las "corretizas" y al que agarraban, le pegaban y le decían: ¿Qué haces en la calle, vago, sedicioso?

Nadie sabía que era ser sedicioso, ni siquiera los policías sabían que era eso. A los más grandes, de 16 para arriba, se los llevaban. Entonces, para que no nos molestaran, empezamos a hacer las cosas en las azoteas. 
Allí había desde pelea de perros hasta crianza de conejos y chinchillas. Mucha gente perdió su virginidad en las azoteas. De hecho, hay un personaje que se llama Chelo, que está haciendo sus cositas ahí, en la azotea en la noche y tiene prisa. Al brincar de una azotea a otra, no calcula bien y se va para abajo, seis metros y se salvó porque cayó de rodillas sobre un coche. Los amortiguadores la salvaron de la muerte pero los dos fémures se le salen como a un pollo rostizado. Y a mí no me tocó ver una muchacha que se cayó así, pero sí a un muchacho que cayo igualito como lo describo. Yo sé cómo es que se salen los huesos. Así se pasaba en las azoteas.

Ahora que volví a ir a las azoteas donde crecí, mi hijo me grabó un pequeño documental de las azoteas, y yo decía, ¿cómo me atrevía a saltar esto? Así estábamos de locos, que nos colocábamos vendas y saltábamos calculando, a ver si éramos valientes o no, con los ojos cerrados. Ahora lo digo, estábamos mal de la cabeza, pues, no sé si siga mal de la cabeza (risas).

La novela no está escrita de manera lineal y solamente contando la historia. Trato de insertar varias cosas que puedan ayudar a entender la novela y que me ayudaron a mí, pues, no sabía de qué se trataba. Yo solo tenía una vaga idea. Soy asesor de los aborígenes australianos y ellos me contaban leyendas, y estas leyendas me ayudaban a mirar que seguía. No es que yo tuviera muy claro para donde iba la novela.

La T3RA: Y cuando uno está dentro de este mundo, se percibe que hay momentos muy viscerales $y$ orgánicos que hacen pensar que hay mucha vivencia autobiográfica en la novela. ¿Qué tan autobiográfica es tu novela con respecto a tu vida en el D.F.?

GA: Esta es una novela que está basada en hechos reales que nunca sucedieron, es vivencial. El otro día fui a presentar la novela en una ciudad de México y levantan la mano y me dicen: Guillermo, lamento que hayas perdido tus padres a tan temprana edad (él replica). Perdona, pero mi papá acaba de cumplir 93 años la semana pasada, mi mamá tiene 88 , ¿de que estas hablando? (risas). ¿Entonces, no es autobiográfica? (en nueva réplica) No, mis papás siguen vivos pero los papás del personaje, no.

Entonces, la gente se confunde, de que si es real o no, y así era la idea. Le coloqué en la novela al personaje el nombre de Juan Guillermo para que dijeran que está contando su vida, pero realmente no. Es más vivencial que autobiográfica.

En la novela hay un perro que se llama "Colmillo" que es la cosa más feroz del mundo. Pero, junto a mí creció un perro lobo que vivía al lado de mi casa, era muy "pazguato". Levantaba la cabeza, te veía y así quedaba, y se volvía a dormir. No hacía nada, era aburridísimo. Pero yo sí tuve a un perro que era loco de carretera, que era el "Coffee". Le puse la personalidad de mi perro a ese perro lobo y, entonces, así sí era muy salvaje. Así funciona la creatividad, fusionar un momento con otro, a través del arco de la imaginación.

La T3RA: Es una novela bastante extensa, son 700 páginas. ¿No crees que eso pueda asustar a quien quiera leerla, al ver su tamaño?

GA: Una vez entre al salón de mi hijo, cuando él tenía 12 años, a dar una plática en sexto de primaria y me llamaron para que les hiciera el favor de promover la lectura. Hice que los maestros salieran del salón y les dije a los estudiantes: muchachos, no le vayan a decir nada a los profesores ni a sus papás lo que les voy a decir. Esto un secreto. Les voy a dar libros 
prohibidos, cuidado los ven con esos libros porque son peligrosísimos. Y si sus papás, se enteran, se van a enojar conmigo. Solo léanlos a escondidas. Cómprenlos y luego, escondan esos libros. No se los dejen ver de nadie.

Los chamacos compraron todos los libros. Si los arzobispos dijeran: no lean el libro de Arriaga porque va contra los valores más profundos, se vendería muchísimo. Este libro trae condón, por lo que salpica tantas cosas. Puede salpicar semen o flujos vaginales, sudor, sangre. Por eso, les ponemos condón a los libros, para que lo abran a escondidas y se salpiquen de lo que quieran. $Y$ eso es lo que creo que debe tener un libro, que cuando lo abras, te salpique algo.

Hay escritores que hacen el libro para que te acaricien la manita, pero, este libro es uno que muerde. Que este libro te hiera, confronte, critique, que te haga sentir cosas y que luego te cure. Porque el mismo libro te puede curar. Esta es una historia de amor y de amistad. Para chavos de 14 a 17 años de edad. Desde qué pasa por no ser vírgenes, hasta que pasa por enamorarse de una mujer que se acuesta con todos. A un tipo que está perdido, que está huérfano, ¿cómo es el abandono?, ¿cuál es la importancia de los amigos?

La T3RA: Precisamente, cuando uno empieza a leer la novela, esta salpica con una lucha de supervivencia en el vientre de una madre en la que hay una muerte. Para tus historias, ¿cómo tomas la decisión de cuál va a ser esa escena inicial con la cual vas a agarrar al espectador, como me paso a mí, que la hojeé y no pude parar de leerla?

GA: Gabriel García Márquez hace algo en la literatura que se llama in media res que es empezar en la mitad de la acción y que a mí me dio una gran lección de literatura y de cine: "muchos años después frente al pelotón de fusilamiento el coronel Aureliano Buendía recordó la remota tarde que su abuelo lo llevo a conocer el hielo". Fíjate, muchos años después frente al pelotón de fusilamiento, al tipo ya lo van a matar, ya está diciendo porqué van a matar a este; pues, ya de entrada, ya te está enganchando. O también: "el día que lo iban a matar Santiago Nassar fue a esperar el buque en el que llegaba el obispo". Quizás uno de los comienzos más hermosos y cacofónicos del maestro García Márquez.

Cuando tú escribes tienes que hacer algo para que lector se sienta enganchado. En este caso, el personaje tiene un gemelo idéntico dentro del vientre materno, y yo no sé si lo sepas, pero los gemelos se pelean dentro de su madre. No crean que se abrazan y se dan caricias. Ellos se patean y luchan por el territorio. Es más, siempre en los gemelos idénticos, siempre hay uno más dominante que el otro. Aquí, en la novela, el gemelo está pateando al otro y, lo patea de tal forma, que provoca que se ahorque con el cordón umbilical para que se muera. La mamá no se da cuenta, pero, uno de los gemelos ya está muerto y está envenenando con su sangre de muerto al que queda vivo, y así empieza la novela. Desde ahí empieza el hombre con un sentido de culpa, porque mató a su hermano, porque los papas se deprimen por la muerte de su hijo y echándole la culpa a su hijo, a pesar de que era solo un pequeño infante. Este muchacho tiene una sensación de ausencia muy grande, que trata de compensar con afecto, amor y amistad.

La T3RA: La novela comienza con muertes y continúan con más muertes, muchas de tus obras tienen la presencia y el ataque de los personajes, desaparición de sus seres queridos que luego son perseguidos a lo largo del relato. ¿Por qué esta continua presencia de la muerte atormentando a los personajes? 
GA: Para empezar, uno no elige los temas, los temas te eligen a ti, y también las obsesiones. No creas que yo me la quiero pasar escribiendo de muerte. Estamos acostumbrados a reprimir la muerte. ¿Sabes por qué estoy calvo? Porque la muerte me dio un lengüetazo, la muerte me dijo, ¿te crees muy de acá? A las mujeres, de pronto se les caen los senos, se les caen los pelos. Empieza la muerte a darnos lengüetazos de varias maneras, pero no lo queremos ver.

Cuando iba en secundaria teníamos un esqueleto humano real y le poníamos nombre, sombrero, corbata; nos daba mucha risa. ¿Qué tal si traemos a un hombre que ha sido atropellado hace tres días? Nadie lo conoce. Tráiganlo y lo colgamos allí y brota de él la muerte, ¿esto los horroriza?... Tenemos un problema con la muerte y creo que para poder entender la vida, hay que entender la muerte. ¿Sabes en que se van a convertir esas manos? En las manos de un cadáver. $Y$ vienen las preguntas: ¿qué he hecho con estas manos que valga la pena?, ¿ya acariciaron las pieles que debían acariciar?, ¿ya construyeron algo?, ¿ya le partieron la cara al que se lo merecía? Yo por eso escribo y me dedico tanto tiempo a escribir, porque esta es mi lucha contra la muerte. Yo tengo mi estudio llenos de calaveras y cuando llego cansado digo: estoy muy cansado; no te vas a morir, has algo con tus manos, deja algo, construye algo. $Y$ por eso me dedico 16 horas a escribir.

La T3RA: Otro elemento clave, como manera de sobrellevar la muerte, es el elemento sexual, que en tus novelas y en tus películas es bastante fuerte. En "El Salvaje" está la descripción de la iniciación sexual de Juan Guillermo, con Chelo, una chica de la que se enamora, pero, que ha tenido que compartir con otros. En tus relatos, ese elemento sexual está enmarcado en relaciones complejas ¿Por qué es tan importante el

\section{sexo en tus narraciones?}

GA: Las dos grandes fuerzas de la vida son el sexo y la muerte. ¿A que le tenemos más miedo en la vida? A la muerte. En las películas de terror me van a matar y yo tengo que huir. ¿Qué es lo que más nos gusta en la vida? El sexo, porque sin sexo no hay vida, punto. A los hombres se nos acaba el deseo sexual a los 50 años, pero, después de muertos pareciera ser que el sexo solo es cosa de los hombres. No nos engañemos, a los dos, hombres y mujeres nos gusta. Y los dos tenemos esa urgencia, es lo que mueve al mundo, el sexo y la muerte, así que, ¿cómo dejar al lado el sexo en una novela?

Todos venimos de una relación sexual. Como mi familia no era una familia conservadora, el pecado no existía, mis padres me dijeron que el pecado más grande era la injusticia, la pobreza, la corrupción y la impunidad, esos son los verdaderos pecados, ¿ por qué el sexo sería pecado? Esta la mejor forma de relacionarnos los seres humanos

La T3RA: Muchos escritores para crear sus mundos y profundizar sus personajes, hacen investigaciones, pero tú tienes un proceso totalmente diferente. ¿Cómo es este proceso?

GA: Yo escribo de lo que conozco y no investigo nada. Yo hice una película que se llama "Babel", que se lleva a cabo en Japón y en Marruecos, y los marroquíes dicen que es la película más marroquí que han visto. Habla de pastores de cabras, que yo creo que se portan igualito como los pastores de cabras mexicanos. Yo me acuerdo que una vez, un campesino analfabeto, muy amigo mío, que se llama Lucho Estrada y que tiene un hermano que se llama Melquiades Estrada, me recibió en su casa y le quise dar dinero para gratificarle, él me dijo: "los 
favores no se cobran", y eso lo puse en la película. Los marroquíes me decían que así es el pueblo de ellos, no te van a cobrar por un favor. En esta novela no investigué, yo hablo sobre cosas que conozco, y si no, lo inventó.

La T3RA: Ya que nombraste a Melquiades Estrada, en tu película "Los tres entierros de Melquiades Estrada", la frontera es casi un punto obligatorio de convivencia entre los mexicanos y los norteamericanos, y sin lugar a dudas, uno de los más difíciles en el globo terráqueo. En tu novela "El Salvaje", también está el paso con la ilegalidad de las drogas y los acuerdos que se hacen entre los americanos y mexicanos, ¿cómo ha sido ese acercamiento ese mundo de la frontera?

GA: Yo voy a la frontera entre México y Estados Unidos como 8 veces por año, porque allí es donde voy de cacería y cazamos tan cerca de la frontera, que cazamos temprano. Regreso a las 10 de la mañana, luego nos vamos a desayunar lentejas, vamos y venimos al supermercado en Texas. Entonces, entramos y salimos, y hay una relación bastante dinámica. Cuando filmé "Los tres entierros de Melquiades Estrada", llevé a algunos de mis alumnos, como práctica de campo, para que supieran cómo era una filmación de una película de Hollywood y fuimos a un bar donde por una hora tocaban música mexicana y, por una hora, música country. $Y$ estábamos sentados los mexicanos y los gringos. $Y$ a una alumna mexicana de una universidad privada, de más o menos de dinero, se le acerca un vaquero gringo:

- ¿Tú eres mexicana?

- Sí.

- Me haces un favor: ¿te casas conmigo?

- ¿Por qué te quieres casar conmigo?

- Porque a las mexicanas le gusta hacer tortillas y tratar bien a sus maridos.

Me dio tanta ternura al ver a estos dos, que no te das cuenta de la interacción tan grande que hay. La frontera es un territorio donde hay bastantes intercambios culturales, de relaciones, de amoríos, hay hijos, hay muchas cosas que hay en la frontera y quienes no la conocen, no se percatan. $Y$ eso es lo que he querido reflejar. Hay cosas terribles, como cuando los inmigrantes cruzan la frontera y dejan a sus hijos chiquitos. Luego, le pagan a un "coyote", -que es como se le llama al tipo que los cruza-, para que los lleven allá, pero, cuando llega la policía de frontera huyen y dejan a niños de 2 años, hasta de meses, ahí, en el desierto y nadie sabe quiénes son, ni quiénes son sus papás y los tienen en orfanatorios, para ver si a los padres se les ocurre ir.

Por eso es que en la película "Babel" coloco a unos niños gringos que quedan abandonados en el desierto, para que los gringos entiendan el dolor de un padre inmigrante por su hijo. También en la frontera pasan cosas como los celos, tú no sabes cómo ellos sufren de celos. Tú trabajas al otro lado y le mandas dinero a tu esposa, sin saber si ella no se está acostando con otro. Y la mujer piensa que el hombre encontró una gringa y se va a quedar con ella allá. Con Pedro Estrada, su mujer Rosa se fue a cruzar y desapareció. No se volvió a saber de ella. Mi compadre Pedro, un campesino analfabeto, del norte de México, se empezó a dejar el pelo largo hasta que la encontré y lloraba cuidando las vacas. Rosa no apareció hasta año y medio después, porque la metieron a la cárcel por un pasaporte falso, porque no es un delito federal cruzar hacia los Estados Unidos. Cuando ella se perdió, no había celulares, y solo había en el pueblo una caseta que quedaba a 30 kilómetros y cuando ella lo llamó, pasaron los tres minutos de la llamada, porque el 
muchacho de la bicicleta se demoraba dos horas de ida y dos horas de vuelta en avisar de la llamada.

La T3RA: Algo relevante en esta película y también en tu novela, es la aparición de la amistad y también el amor. ¿Por qué aparece el amor y la amistad en momentos extremos de tus personajes cuando creen que el abandono es lo único que los rodea?

GA: Hemos "cursificado" el amor y la amistad. Cuando hablamos de amor y la amistad decimos que cursi eres, y no. Sin el amor y la amistad el tejido social se descompone. Es lo que nos da esperanza, es lo que nos permite avanzar en el mundo. Imagínense una vida sin amigos. Con los amigos construimos, porque nosotros no somos nosotros, nosotros somos el amigo de, el hijo de, el esposo de, el hermano de. Nuestra identidad no solo está construida por quien soy yo, sino con quién me relaciono. Por eso, cuando se nos muere alguien que queremos, una parte de nuestra identidad se rompe de tajo. $Y$ yo, sí quiero hacer un énfasis que el amor y la amistad son importantes.

La T3RA: En "El Salvaje", los lazos de amistad, de fraternidad $y$ de amor son interrumpidos por un grupo de fanáticos religiosos llamado "Los buenos muchachos", que juzgan, condenan y ejecutan a aquellos que no tienen una buena moral ¿Cuál fue tu experiencia personal con estos tipos de grupos?

GA: Yo no soy creyente, pero, creo que la religión debe ser un punto de encuentro, no de distancia. Creo que aquel que cree en Dios debe aceptar al otro porque eso es un mandato divino, y no asesinar al otro. En esta novela, hay un grupo que a mí me tocó vivir, que los llamábamos "Los buenos muchachos", que se vestían muy bien, no decían malas palabras, no tenían el pelo largo, no tenían pulseras. Eran el sueño de toda madre.
Pero estos muchachos, golpeaban y entraban a matar gente que ellos consideraban impuros e inmorales: a los ateos, los herejes, los comunistas, las mujeres que eran muy putas, los que vendían drogas. A ellos los perseguían. Yo creo que ellos son gente que está enferma de Dios. ¿Crees que es justo que una persona atropelle a varias personas con una camioneta en Barcelona? Ellos usan a Dios como pretexto para su sociopatía. Esto no puede ser pretexto para asesinar o discriminar a alguien y de esto trata la novela, de la intolerancia, porque estos 'buenos muchachos', que se suponen que son buenos católicos, son los que asesinan al hermano del protagonista y ellos creen que están haciendo el bien, porque están limpiando la escoria a la sociedad porque simplemente son distintos a ellos y por eso lo matan. Es una reflexión sobre el acto de la fe y cómo se debe creer en Dios en una sociedad como en la que vivimos en la actualidad.

La T3RA: Esta novela es un viaje además por Ciudad de México, o el D.F. (Distrito Federal), de la cual has escrito novelas, has hecho películas y que, con seguridad, seguirás escribiendo. Tú viajas bastante alrededor del mundo, pero, tu lugar propio es el D.F. ¿Qué significa para ti el D.F. y para Latinoamérica?

GA: Es una ciudad que tiene entre 22 y 23 millones de habitantes. Es muy paradójica como cualquier ciudad latinoamericana. Yo felizmente nací en esa ciudad, lo cual me brinda historias como esta. Tan solo estar en el tránsito de la ciudad, ya es una forma de violencia. Es una ciudad bastante fuerte, el pasado está muy presente. Vas caminando por el centro y te encuentras con pirámides, con la segunda catedral más grande del mundo, con la segunda plaza más grande del mundo. En México todo debe ser bestia, con la calle más larga del mundo. Además, es la segunda ciudad con más museos, teatros, galerías. Y obviamente, hay zonas 
muy 'fresas' donde los hipsters están tomando el poder.

Por cierto, no sé si aquí en Bucaramanga, pero en muchas ciudades de América Latina que he ido, los jóvenes viven cada vez más protegidos. Dada la violencia que existió, los jóvenes de clase media y media alta se refugiaron en departamentos y como no tienen marcas de cicatrices, ahora su ropa tiene cicatrices. Su ropa viene rota, hay algunas partes donde venden las camisas llenas de grasa, como de mecánico. Cuando yo era joven, los tatuajes solo los tenían los presos y los marineros. Ahora los jóvenes los tienen por la falta de cicatrices. No tuvieron experiencias fuertes en la vida, entonces se pintan para tener cicatrices y su ropa está viviendo la vida que ellos no tienen.

La T3RA: En Amores perros vemos ese choque en el D.F. de distintas clases sociales, donde un accidente hace que se muestren distintas realidades y, luego, cuando va a aparecer "21 gramos", tú diseñas todo el proyecto para hacerlo en el D.F., pero se da la oportunidad de hacerlo con actores de Hollywood y con un presupuesto mayor. ¿Cómo fue el cambio de pasar los personajes y lugares a los Estados Unidos y en general, la experiencia de rodar allá?

GA: Yo me siento muy afortunado de poder trabajar en otros países. Creo que he trabajado con diez de los mejores actores del mundo. He podido trabajar con Brad Pitt, con Sean Penn, con Benicio del Toro, con Charlize Theron, con Jennifer Lawrence. Yo dirigí la primera película de Lawrence, quedamos que yo me iba a quedar con el $90 \%$ de ganancias pero se ha hecho la tonta (risas). También con Kim Basinger, Gael García, Emilio Echeverría, Tommy Lee Jones, Barry Pepper, entonces, sí he tenido la oportunidad de trabajar con grandes actores y grandes fotógrafos.

Lo que hace Hollywood es que es como entrar en una dulcería. Cuando yo dirigí "The burning plain", era como jugar futbol en la calle y decir, yo me pido a Messi, Cristiano y a Higuita, también, o a Valderrama. Puedes escoger a quien tú quieras y en el peor de los casos, es que te digan que sí. Yo le agradezco a Hollywood, a pesar que la gente dice que son las películas malas. Allá hay gente que quiere hacer películas buenas, gente que está comprometida, que tú puedas hacer tu película y yo nunca me he sentido discriminado en Hollywood. Es un privilegio trabajar con estos actores. Una vez estaba caminando en la calle en Los Ángeles, sonó mi teléfono y contesté. Me dicen: hola, Guillermo, soy Tommy Lee Jones, ¿tú hablas inglés? Él me invitó a cenar, me preguntó si quería hacer una película con él, e hicimos juntos "Los tres entierros de Melquiades Estrada".

La T3RA: Hablemos de esa afinidad que pudiste desarrollar con ciertos actores. Tú creas un personaje, le das vida, lo llevas al límite, lo vuelves miserable, lo conoces muy bien y luego viene el proceso de llevarlo a la pantalla. ¿Cómo te parece el resultado del casting de los directores de las películas que escribes y, también, de la elección que tú mismo haces de los actores para tus películas?

GA: Cuando tú escribes una película es como tener una mujer embarazada y cuando nace es: mira, tiene cara de Sean Penn (risas). Hay una regla de oro que aprendí, que es no escribir pensando en actores porque te rompen el corazón cuando te dicen que no. Hay que escribir la película comprometida con el personaje y ya encontraras a la actriz adecuada. Cuando yo escribí "The burning plain", necesitaba un actriz joven. Yo no podía ir a la sesión de casting porque no tenía permisode trabajo para ir a los Estados Unidos y la directora de casting me mandaba un DVD, y yo tenía un mes de búsqueda de reparto. El primer día me manda un DVD y me dice que las ordenó según ella consideró -en 
orden- de las más probables de este día y debía ver 200 actrices. Pero, entre las tres primeras vi a Jennifer Lawrence y me quedé muy sorprendido. Lo más importante en la búsqueda del reparto es el gusto y ella tenía un impecable gusto. A mí me choca cuando un actor en un casting empieza a llorar y eso es para telenovelas. Jennifer, dijo sus líneas sin mover un solo músculo de la cara y sin embargo, conmovía.

Para el actor que elegí para el personaje de JD Pardo, quería ver la química que había entre ellos, así que los reuní a los dos para poder ver la unión que tenían estos dos. La producción me estaba presionando para contratar otra actriz joven que se llama Kristen Stewart, pero yo quería a Jennifer. Yo les dije a JD y a Jennifer, empiecen a actuar. Estaba con la directora de reparto y su asistente. Escucho unos sonidos detrás mío y, al voltearme a verlas, ellas estaban llorando. Se me acerca ella y me dice: los dioses del casting han descendido a este espacio. Fue tan conmovedor que hicieron llorar a estas dos. Me acuerdo que cuando termine la película le escribí una carta a Jennifer, en la que le dije: que no digas que nadie te lo advirtió; vas a ser tan nominada como Meryl Streep, vas a ser la actriz más importante de tu generación, y a ganar muchísimo dinero, por favor, no pierdas piso. Porque si una actriz te hace llorar en una sesión de casting, es porque tiene algo especial. Vas descubriendo diferentes gustos, como los directores que tienen un gusto especial y he podido trabajar con directores con buen gusto. Donde a mí me hubieran puesto en "21 gramos" a Meg Ryan, Robin Williams y Jim Carrey, renunció. Pero Alejandro González tenía buen gusto y eligió a Sean Penn, Benicio del Toro y Naomi Watts. Tommy Lee Jones escogió a Barry Pepper y a Julio Cesar Cedillo. Entonces, el buen gusto es importante o un gusto parecido al tuyo, por lo menos.

La T3RA: Una de las aclaraciones que tú haces vehementemente es no usar la palabra guion, tú prefieres utilizar una 'obra para cine'. ¿Por qué haces esa defensa tan fuerte respecto a esto?

GA: En los años 40 se le decía libro cinematográfico. La palabra guion es despectiva, porque suena a una guía. Yo me tardo tres años en escribir una obra de cine para que me digan: usted hace guion, hace guías... es una basurita. Es un guionista, pero, el tipo que hace las guías del restaurante de Michelin. Yo hago una obra, punto. $Y$ es literatura. Cierto, hay escritores de cine que trabajan como escribanos de lo que el director les dice. Escribe eso y ellos lo hacen, casi les están dictando. Hay otros que no, porque escribimos una obra personal. Los personajes se llaman como mis hijos. En "Babel", la señora se llama Amelia, en honor a mi mamá. Entonces, ¿por qué de pronto te vuelves en el tipo que solo hace una guía?

La T3RA: Guillermo, una última pregunta ¿para ti cuál es la definición de un artista?

GA: Ser un artista es alguien que entra a lo más profundo de los bosques en donde nunca nadie ha ido antes y regresa con algo que nadie ha visto. Nuestra obligación como artista es meternos en lo más profundo en donde nadie quiere meterse. Cuando he dado clases siempre le digo a mis alumnos que al escribir, nunca traten de ser profundos, olvídense de ser profundos. Si tú eres profundo, la historia va ser profunda. Si tú eres superficial, la historia va a ser superficial. Tú cuentas la historia, punto. Cuéntala lo mejor posible. Si es profundo o no es profundo, no está en tus manos. En el arte no hay voluntad. Yo no puedo ponerme a escribir diciendo que voy a hacer una obra maestra. Hay gente que dice que está escribiendo algo muy comercial, ¿ah sí? Entonces, ¿cómo se escribe el próximo Harry Potter y ganar 2.700 millones de libras 
esterlinas?

¿Estás escribiendo para ganarte un Nobel y te cae? ¿Tú crees que Gabo se iba a ganar un Nobel o escribió lo que traía? Aunque creo que el artista debe presentar visiones originales y profundas, no todo el mundo tiene la capacidad de hacerlo y no hay que angustiarse. Chejov dice que uno escribe lo que puede y no lo que quiere. $Y$ uno hace su mejor esfuerzo, y uno se la pasa cinco años y medio escribiendo con la intención de que quede bien, pero, eso no garantiza nada. $\mathrm{Y}$ algunos juzgan sin saber lo que pasó, no hay control sobre la obra y eso es lo bonito de escribir, que no sabes lo que va a pasar, que te sorprende. 